\title{
What Underlies Immersion Students' Production: The Case Of Avoir Besoin De
}

\author{
Sharon Lapkin \\ University of Toronto \\ Merrill Swain \\ University of Toronto
}

\begin{abstract}
One of the advantages of having students work in pairs on language-related tasks is that teachers and researchers can listen to what the students say as they carry out their assigned tasks. What they say offers insights into the students' beliefs about the target language they are learning and using, and reflects the cognitive processes they use to produce an utterance. In this paper, we analyze dialogues between pairs of eighth grade French immersion students about avoir besoin de. Our analysis provides insights that allow teachers to help students more accurately encode the meaning they wish to express. Teachers and researchers are also given an insider's view of how learners make use of what they already know to support their learning of an additional language.
\end{abstract}

\section{Introduction}

Vygotsky (1978) and other scholars since then (e.g., Wertsch, 1985, 1991; also Cole, 1996; Lantolf, 2000a, 2000b), have articulated a sociocultural theory of mind. Their theoretical perspective has been that cognitive functions such as attending, hypothesis testing, reasoning, and voluntary memory are mediated activities, and their origins are social in nature. Cognitive processes first emerge in collective behavior, in cooperation with other people, and then subsequently they become internalized as the individual's own "possessions." The process of internalization is mediated by semiotic tools, of which language is one of the most important. Lantolf (2000b) has pointed out that "Attending to the talk generated by learners during peer mediation allows us access to some of the specific cognitive processes learners deploy to learn a language" (p. 85).

Speaking, of the sort we observe when students engage in solving language problems, is a cognitive activity. Speaking mediates learning. As Wells (2000) pointed out: "One of the characteristics of utterance, whether spoken or written, is that it can be looked at simultaneously as process and product: as 'saying' and as 'what is said"' (p. 73). In saying, the speaker is cognitively engaged in making meaning: A cognitive act is taking place. It is frequently in the effort of saying that a speaker "has the feeling of reaching a fuller and clearer understanding for him or herself" (p. 74). Saying, however, produces an utterance that can now be responded to-by others or by one's self. What was said becomes an objective product that can be explored further by the speaker or others (see Swain, 2000, p. 102).

In this article, we provide examples of dialogues in which utterances are both process and product. As process, speaking transforms the students' cognitive processes into observable activ-

Sharon Lapkin (PhD, University of Toronto) is Professor in the Second Language Education program, Ontario Institute for Studies in Education of the University of Toronto, Ontario, Canada.

Merrill Swain (PhD, University of California, Irvine) is Professor in the Second Language Education program, Ontario Institute for Studies in Education of the University of Toronto, Ontario, Canada. 
ity. As product, what the students say becomes fodder for reflection and a basis for further mental action. The cognitive processes that such dialogues reveal should help researchers to understand what underlies language use and language acquisition.

Our working hypothesis is that the dialogues that students engage in while solving language-related problems offer evidence of the cognitive processes and strategies learners use to produce an utterance, and represent their beliefs about how the target language works. The dialogue is not "enhancing" learning, or leading to learning, it is learning. In other words, learning is a continuous process of constructing and extending meaning and meaning-making tools which occurs when learners are speaking in joint problem-solving activities (Wells, 1999).

\section{Reformulation}

Reformulation was defined some 20 years ago by Cohen (1983, p. 4) as "having a native writer of the target language rewrite the learner's essay, preserving all the learner's ideas, making it sound as nativelike as possible." This is an excellent way of providing feedback to learners on lexical, grammatical, and discourse improvements that could be made to their written piece. Learners engage in an active process of discovery as they notice differences between their text and the reformulated version; moreover, the reformulated text provides a target language model of content they themselves have generated-motivating learners further to attend to differences between the texts (see, e.g., Allwright, Woodley, \& Allwright, 1988).

The benefits of reformulation have been outlined in many studies (e.g., Adams, 2003; Lapkin, Swain, \& Smith, 2002; Qi \& Lapkin, 2001; Thornbury, 1997). Adams (2003) replicated the Swain \& Lapkin (2002) study with university students of Spanish using a research design which made it possible for her to separate out the effects of task repetition alone (students only wrote the pretest and the posttest), noticing (students, after writing the pretest, compared their writing to that of a reformulated version, then wrote the posttest), and stimulated recall (students wrote the pretest, noticed the differences between their writing and the reformulation of it, and then immediately recalled what they were thinking at the time of their noticing stimulated by listening to a recording of their noticing session). The posttest score for each learner was calculated as a proportion of reformulations that were incorporated in a more targetlike form to the total number of reformulations. Both the Noticing Group and the Noticing + Stimulated Recall Group significantly outperformed the Task Repetition Group. A further analysis compared the proportion of more targetlike incorporated reformulations to reformulations that the learners had reported noticing. Here the Noticing + Stimulated Recall group significantly outperformed the Noticing Group. These findings suggest that noticing the feedback provided by the reformulation had an effect on the final scores students obtained, and that the stimulated recall had an impact above and beyond that of noticing the feedback.

The task we used in the study reported here incorporated multiple opportunities to revisit problematic language items and structures (see also Lapkin et al., 2002), and multiple opportunities for learners to talk collaboratively and productively about them.

\section{Study}

We worked with four pairs of eighth grade French immersion students who were drawn from a single class in a middle school in the greater Toronto area. These were middleclass students who had begun language immersion in kindergarten. In the first few years of schooling, all instruction was provided through the medium of French, the L2. English language arts was introduced at about third grade, and by fifth grade the instructional day was divided evenly between subjects taught in French and in English.

The teacher who had taught these students in seventh grade the previous year, along with their eighth grade teacher helped us choose eight students for the current study. The seventh grade teacher also constituted the pairs. ${ }^{1}$ The seventh and eighth grade teachers rated the proficiency level of the students, using a seven-point scale with 7 representing a high level of overall proficiency in French (i.e., the teachers' perception), and 1 indicating a low level of overall proficiency in the target language. ${ }^{2}$ The participants' pseudonyms and proficiency ratings as assigned by the teachers are shown in Table 1.

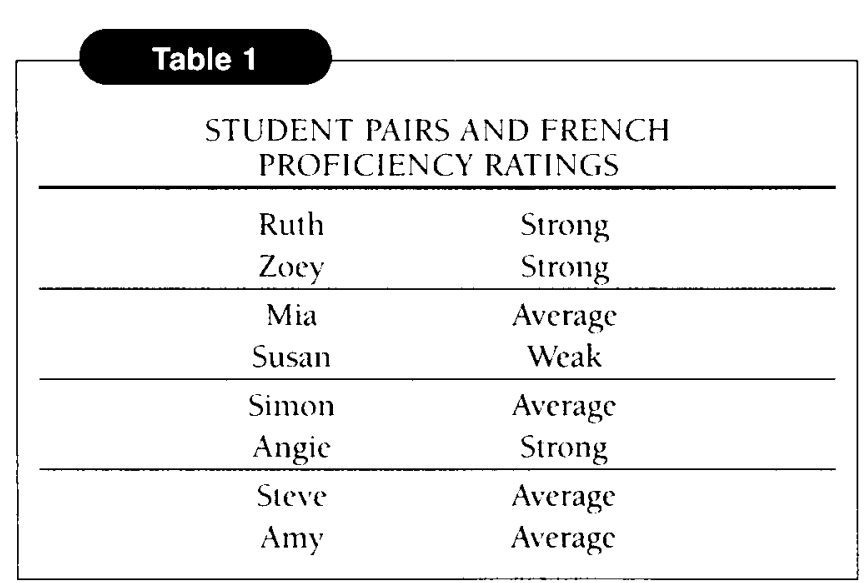

Information about the task is presented in Table 2. For the purposes of this paper, only the bolded items are relevant and we provide an abbreviated description of the study design.

Pairs of students were asked to imagine that their school had been given $\$ 2,000$ and that they could have some input as to how the money should be spent. They were asked to spend some time brainstorming ideas and 
Table 2

DATA COLLECTION: TASK STAGES AND PRODUCTS

\begin{tabular}{|c|c|c|c|c|c|c|}
\hline & Stage 1 & Stage 2 & Stage 3 & Stage 4 & Stage 5 & Stage 5 \\
\hline $\begin{array}{l}\text { Data } \\
\text { Collection } \\
\text { Stages }\end{array}$ & $\begin{array}{l}\text { Saynete } \\
\text { (role play) }\end{array}$ & $\begin{array}{l}\text { Transcribing } \\
\text { (Students tran- } \\
\text { scribe stage } 1 \\
\text { tape) }\end{array}$ & $\begin{array}{l}\text { Noticing } \\
\text { (Students com- } \\
\text { pare their tran- } \\
\text { scription to a } \\
\text { reformulation) }\end{array}$ & $\begin{array}{l}\text { Stimulated } \\
\text { Recall } \\
\text { (Students view } \\
\text { their noticing } \\
\text { session and } \\
\text { comment) }\end{array}$ & $\begin{array}{l}\text { Students redo } \\
\text { their role play; } \\
\text { students rewrite } \\
\text { their pretest } \\
\text { individually } \\
\text { (= posttest) }\end{array}$ & $\begin{array}{l}\text { Interview } \\
\text { (individual) }\end{array}$ \\
\hline Products & $\begin{array}{l}\text { 1. Video- and } \\
\text { audio-record- } \\
\text { ed oral role } \\
\text { play' }\end{array}$ & $\begin{array}{l}\text { 2. Transcript of } \\
\text { transcribing } \\
\text { session } \\
\text { 3. Transcribed } \\
\text { role play* } \\
\text { (pretest) } \\
\text { 4. Reformulation }\end{array}$ & $\begin{array}{l}\text { 5. Transcript } \\
\text { of noticing } \\
\text { session } \\
\text { 6. Highlighted } \\
\text { reformulation } \\
\text { 7. Students own } \\
\text { annotated } \\
\text { transcript (\#3) }\end{array}$ & $\begin{array}{l}\text { 8. Transcribed } \\
\text { stimulated } \\
\text { recall }\end{array}$ & $\begin{array}{l}\text { 9. Transcript } \\
\text { of oral role } \\
\text { play }\end{array}$ & $\begin{array}{l}\text { 12. Interview } \\
\text { student A } \\
\text { 13. Interview } \\
\text { student B }\end{array}$ \\
\hline
\end{tabular}

then to do a role play involving a meeting with the principal (our research assistant) to present their ideas. The role play took about 3 to 6 minutes (Stage 1). It was video and audio recorded. After a short training session on how to use a transcriber (using an unrelated recorded text), the students transcribed their role play ${ }^{3}$, yielding product 3 in Table 2. That transcript or pretest was reformulated by a native speaker of French (product 4). In Stage 3, the students compared a typed version of their pretest to the reformulation, noticing differences between the two. In Stage 4, the researcher stopped the tape from the previous session where noticing had taken place, and asked the students to reflect aloud on what they were thinking as they noticed differences between the two texts. During Stage 5, students were given the opportunity to do their role play again orally; then each student was given the pretest and they rewrote it, individually, making any changes they wished. This was the posttest (products 10 and 11, Table 2).

We watched all of the videotapes and carefully read through all of the transcripts. We found a number of errors that were surprising and have focused on one of these here.

We analyzed all the transcripts using MonoConc Pro (Barlow, 1999) concordancing software, pulling out all instances of besoin in our corpus. In this way, we could locate instances of avoir besoin de and trace its use throughout all the task stages, examining the accuracy of this "locution verbale" (Wilmet, 1997). As will be seen, some students did not seem to know that avoir is an integral part of the verb phrase, and behaved as if the nominal besoin was a direct translation of the English verb "to need." The fact that some of the students equated besoin and the English verb "need" gave rise to related language problems. ${ }^{4}$

\section{Data Analysis and Interpretation}

In this section, we analyze one pair's dialogue-that of Ruth and Zoey-relating to avoir besoin de, making reference on occasion to the other pairs to support our interpretation of the data. Ruth and Zoey appeared to have a twofold hypothesis about this verb phrase: (1) besoin is a main verb; and (2) avoir is an auxiliary marking past time (i.e., they think that avoir is not a main verb, as it actually is in avoir besoin de).

During the noticing session (see Table 2), Ruth and Zoey had two sheets in front of them: one was their original role play as they had transcribed it, and the other was the reformulation, printed on contrasting colored paper. In the relevant part of the session, the students noticed that $a$ was missing from what they had written. In turn 40 , Zoey began to read from the reformulated text and Ruth completed the phrase in turn $41: 5$

40. Z: On a pensé qu'on a...

41. R: Besoin de.

42. Z: Oh, qu'on a besoin. Qu'on a besoin.

43. R: Oh, oui, a est pas là.

In turn 42 , Zoey repeated the verb phrase, emphasizing the $a$ in her first repetition. Ruth then (turn 43) verbalized the difference that Zoey emphasized, noticing that $a$ was missing from their original text. Ruth and Zoey took this up at length in the stimulated recall session, in a 19-turn exchange. The first part of this exchange consisted of five turns:

79. Z: "On a pensé qu'on besoin et puis." Here it says "qu'on a besoin de"

80. R: "De comme" [looks at the reformulation] On a oublié le a. 
81. Z: Qu'on ... on a besoin ... on besoin Iprivate speech $]^{6}$

82. R. "Qu'on a besoin de" [reading the reformulation] "qu'on besoin" [reading the original] . . . We need it. [private speech]

83. Z: We need [private speech]

In turn 79, Zoey read first from their transcribed role play and then from the reformulation, comparing the two. In turn 80, Ruth observed again (as she had in the noticing session) that they had omitted the $a$ in Qu'on besoin. Zoey tried out both alternatives in turn 81 , and Ruth repeated the correct verb phrase as she read from the reformulation in the first part of turn 82 . She then repeated their original phrase (qu'on besoin) and translated it. Zoey echoed her, repeating "we need" quietly.

In the next excerpt, the researcher asked the students to tell her the difference between on besoin and on a besoin.

84. Rl: What would be the difference between the two?

85. Z: Uhm ... on besoin [private speech] . . présent

[looks at R, uncertain]

86. R: Probably?

87. Z: On a besoin. [private speech] . . . Passé composé? [uncertain, looks at $\mathrm{R}, \mathrm{R}$ looks at $\mathrm{Z}$ puzzled] . . . No.

88. R: No, no, it's a

89. Z: . . Qu'on besoin [private speech]

90. R: L'ai, tu as, il a, nous ... [private speech]

91. Z: Qu'on [private speech]

92. R: Non, non, c'est correct. C'est passé composé.

93. Z: Oui?

94. R: Yeah, 'cause j'ai, tu as, il a

In turn 85, Zoey articulated the hypothesis that on besoin is the present tense and that on a besoin is passé composé (turn 87). Both students appeared puzzled. Thus Ruth (turn 86) thought that Zoey's hypothesis, on besoin = present tense, was "probably" right. When Zoey articulated the alternative hypothesis (turn 87) that on a besoin = passé composé, it triggered Ruth to conjugate the verb avoir in turn 90, and then assert in turn 92 that the form they were discussing was indeed passé composé because, as she explained (elliptically) again in turn 94, that is how the passé composé is formed.

It seems clear from Ruth's emphasis and her "[be]cause" (in turn 94) that she viewed the conjugated forms of avoir as markers of past tense, as an auxiliary for the "main verb" besoin. Zoey, who had been uncertain throughout the exchange, continued to express uncertainty: 95. Z: ... [looks uncertain] Oui. I know. But it doesn't seem like this [besoin] was the verb there. [both laugh] seems like avoir is ...

96. Rl: Uh-huh.

97. Z: It's on a. Avoir c'est . . le verbe.

From turns 85 to 97 , although the students were interacting in each other's company, they seemed to be on different tracks. Zoey hesitated and decided finally, correctly, that avoir is the verb; Ruth also hesitated but decided that avoir is an auxiliary marking past time. The two columns listing key turns for each student in Table 3 help make this clear. Although each student appears to follow her own line of reasoning, they are using each other as sounding boards and are fully engaged with each other-as is obvious to anyone watching the video.

The excerpts we reviewed made it clear that it was through their collaborative dialogue that Ruth fully articulated her hypothesis and Zoey consolidated her knowledge (see Swain \& Lapkin, 1995). By consolidating her knowledge; we mean the use by the learner of something she knows partially, or without confidence; further use of it solidifies her knowledge so that she can use it automatically without error. Over time, the learner becomes more and more confident in using it. This may happen over a short period, or a much longer time frame.

Table 3

KEY TURNS FROM RUTH AND ZOEYS STIMULATED RECALL PROTOCOL

\begin{tabular}{|c|c|}
\hline Zoey & Ruth \\
\hline \multicolumn{2}{|c|}{ 85. On besoin...présent } \\
\hline \multicolumn{2}{|c|}{ 87. On a besoin ...passé compose } \\
\hline & 88. No, it's a \\
\hline \multicolumn{2}{|c|}{ 89. Qu'on besoin } \\
\hline & 90. Jai, tu as, il a, nous. \\
\hline \multicolumn{2}{|c|}{ 91. Quion } \\
\hline & 92. Non, non, c'est comect. C'est passé composé \\
\hline $\begin{array}{l}\text { 95. } \mathrm{Bu} \\
\text { th }\end{array}$ & \\
\hline
\end{tabular}


Swain (1997) has defined collaborative dialogue as "the joint construction of language - or knowledge about language-by two or more individuals" as they confront and solve language problems (p. 115; see also Swain, 2000). Without the opportunity to work collaboratively, to use each other as sounding boards, the cognitive processes of hypothesis formulation and testing, and knowledge consolidation might not have taken place. What the students were thinking would have remained invisible. In fact, the thoughts might never have occurred.

Returning to the twofold hypothesis--besoin is a verb, and avoir is the auxiliary needed to form past tense-we found additional evidence for its validity in the data of two other pairs. ${ }^{7}$ Both pairs treated besoin as an $-e r$ verb! ${ }^{8}$ Mia and Susan produced $t u$ besoins (ending in $-s$ ) on five occasions in their writing, respecting the rule that $s$ marks the second person singular form in French verbs. Second, in their oral posttest (product 9; see Table 2), Simon and Angie use the form [on] besoinait, the form of the imparfait for first conjugation (-er verbs), and indeed, all French verbs.

The hypothesis that avoir marks past tense in avoir besoin de gets further support in the following excerpt from the stimulated recall protocol of Simon and Angie. Angie reasoned as follows:

232. Yeah, we we had written on, on besoin. And on besoin that doesn't really make sense. Like it's, it's just not the way that you can write "et on besoin." You can't you can't really write like that unless like et ils ont besoin with a $t$ at the end of $o-n$. 'Cause that's actually the way that you are supposed to write the verb, ... conjugate the verb. And ... but ... this was actually in passé composé and ... we ... had missed the $a$... between the on and besoin. Alors, so we had to put the $a$ in the middle of that.

Angie moved from realizing that on besoin "doesn't really make sense" to suggesting that a form of avoir is needed (ils ont besoin) because "that's actually the way that you are supposed to . . . conjugate the verb." But her reasoning then faltered, as she asserted that a form of avoir was indicated because the verb was in passé composé.

\section{Discussion}

As we stated initially, one of the advantages of having students work in pairs on language-related tasks is that teachers and researchers are able to listen to what the students say as they carry out their assigned tasks. What they say offers insights into the students' beliefs about the language they are learning and using. What insights can we articulate from the dialogues we have presented in this paper?

First, we learned that the sorts of errors the students make in using the locutions verbales involving avoir do not arise because of a lack of knowledge about how to conju- gate verbs and in particular -er verbs. The students can generalize the patterns they know (e.g., - s marks second person singular; -ait forms the imperfect in third person singular, etc.) even to nonverbs!

Secondly, we also learned that these immersion students know the rule for forming passé composé. Although they do not use the metalinguistic terminology of "auxiliary," they know that avoir can be a past time marker.

Thirdly, we learned that the basis of their misuse of avoir besoin de is that an equation is made by the students that "need (verb) = besoin (noun)."

The tendency for immersion students to map French onto English structures is well documented. For example, Harley (1992) noted:

The learners appear to make a general assumption that verb meanings will be equivalent in English and French; while this is a useful working hypothesis in many instances, it tends to lead to errors where there is only partial congruence between the two languages. (p. 180)

Thus making use of language awareness techniques such as contrastive analysis would seem to be the most direct and useful way to help these learners accurately use the "avoir" expressions. We discussed this and other pedagogical possibilities with our research team, including six teachers of immersion and core French.

During the discussion, we realized how complex it would be to teach the locutions verbales involving avoir without using metalinguistic terminology. For example, nouns are involved in two-part verbs or verb phrases such as avoir besoin de, avoir faim, avoir soif, avoir peur, while adjectives are involved in avoir chaud, avoir froid. The teachers felt that teaching the metalinguistic terminology would be key to successfully teaching the contrastive points. Having learned what they had about the cognitive processes underlying the errors the students were making, the teachers also felt that reinforcing the characteristics of French verbs (most of which fall into three groups) would be important; no verb, even the so-called irregular verbs, bears any resemblance in form to besoin. Equipped with a better understanding of student errors relating to besoin, the teachers felt that they would be in a better position to scaffold the learners.

Ruth and Zoey's deliberations about avoir besoin de extended over 23 turns, counting both the noticing and stimulated recall excerpts we examined. The opportunity for verbalization was key in allowing Zoey to consolidate her knowledge of the correct verb phrase and Ruth to articulate her incorrect hypothesis which could then be taken up by Zoey and/or the teacher. This verbalization or output included instances of private speech, where Zoey, in particular, was formulating and testing hypotheses (see Swain \& Lapkin, 1995). Students' output here is important evidence 
of what they know and do not know and where instruction is needed (see Swain \& Lapkin, 1998; 2002). The important pedagogical lesson is that we should listen to what our students say, and we should use their mistakes to inform instruction.

\section{Acknowledgments}

This research was made possible by a grant to Merrill Swain and Sharon Lapkin by the Social Sciences and Humanities Research Council of Canada (grant \# 410-990269). The French teachers who formed part of our research team included: Carole Bracco, Karen Devonish, Melanie Heads, Margaret Hearnden, Pam Marshall, and Deborah Monti. Natalia Senatarova was also a research assistant on the project. Lindsay Brooks did the concordancing and participated in all phases of the project, as did Agustina Tocalli-Beller. We wish to express our gratitude to all these teacher/researchers. We would also like to thank Raymond Mougeon and Katherine Rehner for some early, helpful input to this paper. We are also grateful to the participating principal, teachers, and students.

\section{Notes}

1. One reviewer suggested that we provide more information about how the pairs worked: For example, did the two strong students do the task differently from the average/weak pair? We agree that this information is important and our planned future analyses will certainly focus on this issue.

2. Only the end points of the 7-point scale were labeled.

3. Working with adult students of English for Academic Purposes, Lynch (2001) had his students perform a role play and then transcribe it. After they had edited their transcript, Lynch reformulated it and asked his students to notice differences between their transcript and the reformulated version.

4. The present study did not include an observational component. Rehner (personal communication, December 2002) found 39 uses of avoir besoin de on the part of teachers in a study involving 9 third-grade and 10 sixth-grade immersion classrooms (Allen, Swain, Harley, \& Cummins, 1990). A full day (in the case of third grade) and the French portion of the day (in the case of sixth grade) of audiotaping was done in each of these classrooms. This suggests, then, that immersion students have been exposed to this verb phrase quite regularly during their elementary schooling

5. The transcription conventions used include the following:

$\mathrm{R}=$ Ruth; Z = Zoey; R1 = Research assistant

Italics are used for words/utterances in French.

Square brackets are used for our observations.

Quotation marks enclose sentences that are being read aloud (from the transcribed role play or reformulation).

Boldface type indicates emphasis.

Underlining indicates that there is overlapping or simultaneous speech.
6. To identify instances of private speech, we used SavilleTroike's (1988) criteria: no eye contact while speaking, no apparent expectation of response, and a low volume of speech.

7. The fourth pair, Steve and Amy, have clearly learned avoir besoin de, since there are no errors in the use of the verb phrase in their protocol.

8. One of the anonymous reviewers of this manuscript pointed out that "an equally persuasive hypothesis is that the students have interpreted besoin as an irregular verb like prendre or venir, both of which contain an $\mathrm{n}$ in the stem. Could not $t u$ besoins and il besoinait be based on . . . tu viens and il venait?" This is an interesting point; however our experience suggests that immersion students rarely distinguish among the three verb conjugations in French, and do not master many irregular verbs.

\section{References}

Adams, R. (2003). L2 output, reformulation and noticing: Implications for IL development. Language Teaching Research, 7, 347-376.

Allen, P., Swain, M., Harley, B., \& Cummins, J. (1990). Aspects of classroom treatment: Toward a more comprehensive view of second language education. In B. Harley, P. Allen, J. Cummins, $\& \mathrm{M}$. Swain (Eds.), The development of second language profciency (pp. 57-81). Cambridge, UK: Cambridge University Press.

Allwright, R. L., Woodley, M-P., \& Allwright, J. M. (1988). Investigating reformulation as a practical strategy for the teaching of academic writing. Applied Linguistics, 9, 336-356.

Barlow, M. (1999). MonoConc Pro (Version 1.0) [Computer Software]. Houston, TX: Athelstan.

Cohen, A. D. (1983). Reformulating compositions. TESOL Newsletter, 17, 1-5.

Cole, M. (1996). Cultural psychology: A once and future discipline. Cambridge, MA: Belknap Press.

Harley, B. (1992). Patterns of second language development in French immersion. Journal of French Language Studies, 2, 159-184.

Lantolf, J. P. (Ed.) (2000a). Sociocultural theory and second language learning. Oxford, UK: Oxford University Press.

Lantolf, J. P. (2000b). Second language learning as a mediated process. Language Teaching, 33, 79-96.

Lapkin, S., Swain, M., \& Smith, M. (2002). Reformulation and the learning of French pronominal verbs in a Canadian French immersion context. Modern Language Journal, 86, 485-507.

Lynch, T. (2001). Seeing what they meant: Transcribing as a route to noticing. ELT Journal, 55, 124-132.

Qi, D., \& Lapkin, S. (2001). An inquiry into the effects of noticing in a three-stage second language writing task. Journal of Second Language Writing, 10, 277-303.

Saville-Troike, M. (1988). Private speech: Evidence for second language learning strategies during the 'silent' period. Journal of Child Language, 15, 567-590.

Swain, M. (1997). Collaborative dialogue: Its contribution to second language learning. Revista Canaria de Estudios Ingleses, $34,115-132$. 
Swain, M. (2000). The output hypothesis and beyond: Mediating acquisition through collaborative dialogue. In J. P. Lantolf (Ed.), Sociocultural theory and second language learning (pp. 97-114). New York: Oxford University Press.

Swain, M., \& Lapkin, S. (1995). Problems in output and the cognitive processes they generate: A step towards second language learning. Applied Linguistics, 16, 371-391.

Swain, M., \& Lapkin, S. (1998). Interaction and second language learning: Two adolescent French immersion students working together. Modern Language Journal, 83, 320-337.

Swain, M., \& Lapkin, S. (2002). Talking it through: Two French immersion learners' response to reformulation. International Journal of Educational Research, 37, 285-304.

Thornbury, S. (1997). Reformulation and reconstruction: Tasks that promote 'noticing.' EST Journal, 51, 326-335.

Vygotsky, L. S. (1978). Mind in society: The development of higher psychological processes. Cambridge, MA: Harvard University Press.

Wells, G. (1999). Dialogic inquiry: Toward a sociocultural practice and theory of education. Cambridge, UK: Cambridge University Press.

Wells, G. (2000). Dialogic inquiry in education: Building on the legacy of Vygotsky. In C. D. Lee and P. Samgorinsky (Eds.), Vygotskian perspectives on literacy research (pp. 51-85). New York: Cambridge University Press.

Wertsch, J. V. (1985). Vygotsky and the social formation of mind. Cambridge, MA: Harvard University Press.

Wertsch, J. V. (1991). Voices of the mind. Cambridge, MA: Harvard University Press.

Wilmet, M. (1997). Grammaire critique du français. Paris: Duculot. 